\title{
Pendampingan Kelompok Tani "Pintoe Rimba" Desa Naga Umbang, Aceh Besar melalui Optimalisasi Pengolahan Minyak Herbal Tradisional
}

\section{(Mentoring Program for "Pintoe Rimba" Farmer Group, Naga Umbang Village, Great Aceh through Optimalization of Traditional Herb Oil Processing)}

\author{
Kiman Siregar ${ }^{*}$, Ruka Yulia ${ }^{2}$, Sholihati ${ }^{3}$ \\ 1 Program Studi Teknik Pertanian, Fakultas Pertanian,Universitas Syiah Kuala, \\ Jl. Tengku Hasan Krueng Kalee No. 3 Kopelma Darussalam, Banda Aceh 23111. \\ 2 Program Studi Teknologi Pangan, Fakultas Teknologi Pertanian, Universitas Serambi Mekkah, \\ Jalan Tengku Imum Lueng Bata Desa Bathoh, Banda Aceh 23249. \\ 3 Prodi Teknik Industri Pertanian, Fakultas Teknologi Pertanian, Universitas serambi Mekkah \\ Jalan Tengku Imum Lueng Bata Desa Bathoh, Banda Aceh 23249. \\ *Penulis Korespondensi: ksiregar.tep@unsyiah.ac.id \\ Diterima September 2019/Disetujui Maret 2020
}

\begin{abstract}
ABSTRAK
Kelompok tani Pintoe Rimba Desa Naga Umbang, Kecamatan Lhoknga, Aceh Besar membuat minyak herbal tradisional dengan alat yang konvensional dan pengemasan sederhana. Mutu minyak herbal tradisional yang dihasilkan belum terstandar. Produksinya tidak dilakukan setiap hari karena kurangnya peralatan dan pengetahuan. Tujuan pendampingan kelompok tani Pintoe Rimba adalah untuk mengoptimalkan proses pembuatan minyak herbal tradisional menggunakan peralatan distilasi. Hal ini merupakan upaya peningkatan keterampilan, standar mutu, keberlanjutan produksi, dan ekonomi di kelompok tani. Tahapan pelaksanaan kegiatan ini meliputi: 1) Sosialisasi kegiatan; 2) Penyuluhan mengenai peningkatan ekonomi keluarga dan wirausaha; 3) Pelatihan mendesain kemasan dan pelabellan; dan 4) Pengoptimalan pembuatan minyak herbal dengan menggunakan alat destilasi. Hasil dari kegiatan adalah: a) Mitra memiliki pengetahuan mengenai peningkatan ekonomi keluarga dan wirausaha; b) Mitra mampu mengemas dan memberi label pada produk minyak herbal tradisional yang diproduksi dengan menggunakan sealer yang lebih modern; c) Mitra pengabdian mampu menggunakan alat destilasi yang dapat meningkatkan produksi minyak herbal tradisional; dan d) Mitra pengabdian menghasilkan minyak herbal dengan standar mutu yang lebih baik.
\end{abstract}

Kata kunci: destilasi, minyak herbal, optimalisasi, peningkatan ekonomi, pengemasan, pintoe rimba

\begin{abstract}
"Pintoe Rimba" farmer group of Naga Umbang, Lhoknga Subdistrict, Aceh Besar makes traditional herbal oils with the conventional method and simple packaging. The quality of traditional herbal oil produced has not been standardized. Its production is not carried out every day due to the lack of equipment and knowledge. The mentoring of "Pintoe Rimba" farmer group conducted by the team for optimizing the process of making traditional herbal oils using distillation equipment as an effort to improve skills, quality standards, sustainable production, and economy in the farmer group. The stages of this mentoring include: 1) Socialization; 2) Counseling about entrepreneurs for increasing economic; 3) Training in packaging and labeling; and 4) Optimizing the making of herbal oil by using distillation equipment. The outcomes of this mentoring are a) The partners have knowledge about improving the entrepreneurial economy for their family, b) The partners are able to package and label the traditional herbal oil product using a sealer, c) The partners are able to use distillation equipment that can increase traditional herbal oil production; and d) The partners can produce herbal oil with better quality standards.
\end{abstract}

Keywords: distillation, economic enhancement, herb oil, optimalization, packaging, pintoe rimba

\section{PENDAHULUAN}

Indonesia merupakan negara yang kaya akan sumber daya alam. Salah satunya adalah bahan- bahan alam yang dapat dimanfaatkan menjadi berbagai sumber pengobatan, seperti cengkeh, jahe, kencur, dan lain sebagainya. Penggunaan bahan alami sebagai obat tradisional memiliki 
prospek yang sangat cerah di masa yang akan datang. Beberapa faktor yang mendukung hal ini di antaranya 1) Tersedianya sumber kekayaan alam Indonesia dengan keanekaragaman hayati yang sangat melimpah; 2) Sejarah pengobatan tradisional yang sudah semenjak dahulu kala diturunkan secara turun temurun oleh nenek moyang kita; 3) Adanya isu global "back to nature" yang mendorong peningkatan pasar produk herbal termasuk di Indonesia; 4) Menurunnya tingkat perekonomian masyarakat, sehingga masyarakat banyak beralih ke pengobatan tradisional dan herbal. Menurut Supardi \& Susyanty (2010) pengunaan obat tradisional dari tanaman obat-obatan meningkat selama 7 tahun terakhir dari 15,2 menjadi 38,3\%.

Salah satu penggunaan bahan alami adalah untuk membuat minyak herbal tradisonal yang dapat digunakan untuk pijat dan urut. Kedua hal ini telah lama menjadi bagian yang tidak terpisahkan dari budaya Indonesia dan dipercaya memberikan manfaat kesehatan dan kecantikan baik luar maupun dalam. Selama berabad-abad yang lalu di Indonesia, istilah pijat dan urut telah lama dikenal. Hal ini dibuktikan dengan relief batu Borobudur yang ada di Jawa Tengah, di mana terdapat ukiran raja dan ratu yang sedang dipijat oleh dayang-dayang. Pijat merupakan cara tradisional yang digunakan untuk relaksasi dan meringankan rasa tubuh dengan melemaskan otot-otot yang kaku dengan gerakan meremasremas. Selain itu, pijat juga dapat mengurangi nyeri haid pada wanita (Paryono \& Prihati 2017), optimalisasi tumbuh kembang bayi (Karo \& Kaban 2019) dan mengurangi tekanan darah tinggi (Rezky et al. 2015) dan meningkatkan produksi ASI (Hanum et al. 2015). Urut juga digunakan untuk mengobati cidera yang lebih serius dan patah tulang. Urut tidak hanya pada otot namun juga jalur saraf, tujuannya adalah mendorong sirkulasi darah yang lebih baik (Rusnoto et al. 2005).

Pengembangan minyak tradisional di Aceh telah banyak dilakukan, salah satunya yang dilakukan oleh Arpi (2013) yang mengembangkan minyak pliek $u$ atau minyak kelapa sawit sebagai bahan baku pembuatan minyak kemenyan dengan lama pemanasan dua jam menghasilkan minyak kemenyan yang hampir sama mutu kimia dan organoleptiknya, kecuali kandungan iod yang tinggi pada minyak kemenyan dari kelapa sawit. Penelitian lain yang dilakukan oleh Setyawan et al. (2012) pada kencur, yaitu membuat minyak atsiri dari kencur di mana hasilnya perbandingan serbuk kencur; etanol; lama operasi berpengaruh pada yield dan kualitas minyak atsiri. Kondisi optimal ekstraksi terdapat pada perbandingan serbuk kencur: etanol adalah 1:4 dan waktu ekstraksi 3,62 jam. Beberapa tanaman lainnya telah dikembangkan menjadi minyak atsiri seperti daun surian (Juniarti et al. 2011), kayu cendana (Dahlian \& Hartoyo 1998), rimpang jeringau (Effendi \& Widjanarko 2014), bunga cengkeh (Prasetyo 2018), kulit jeruk purut (Iryani \& Deka 2018) dan akar wangi (Al Hanief et al. 2013).

Salah satu kelompok tani yang berusaha mengembangkan pembuatan minyak herbal tradisional berbahan alami seperti cengkeh, jahe, dan kencur adalah kelompok tani Pintoe Rimba Desa Naga Umbang, Kecamatan Lhoknga, Aceh Besar. Permasalahan yang ada adalah kelompok tani ini adalah masih menggunakan cara tradisional yang sederhana dalam proses pembuatan minyak herbal, sehingga belum memberikan hasil ekonomi secara nyata. Padahal jika produk ini dapat dikembangkan secara maksimal maka besar kemungkinan dapat menjadi salah satu produk komersial di masa yang akan datang. Sementara ini kelompok tani Pintoe Rimba membuat minyak herbal tradisonal dengan menumbuk bahan dasar cengkeh, kencur, dan jahe lalu dicampurkan dengan minyak tanah untuk penyakit kembung perut dan dicampur dengan minyak makan sebagai obat urut/pijat.

Rendahnya pengetahuan serta keterampilan dalam membuat minyak herbal tradisional yang lebih modern, belum terstandarnya mutu minyak herbal tradisional yang dihasilkan, minimnya peralatan pembuatan minyak herbal sehingga produksi minyak herbal tidak dilakukan setiap hari, masih sederhananya sistem kemasan minyak herbal yang dihasilkan mendorong tim pengabdian untuk melakukan kegiatan pendampingan kepada kelompok petani pintoe rimba Desa Naga Umbang, Kecamatan Lhoknga, Aceh Besar melalui pengoptimalan pembuatan minyak herbal agar dapat meningkatkan standar mutu minyak herbal tradisional serta menjamin adanya keberlanjutan produksi minyak herbal sehingga pada akhirnya mampu meningkatkan standar ekonomi kelompok tani.

Berdasarkan permasalahan yang diangkat tersebut, mendorong tim pengabdian memberikan solusi permasalahan yang selanjutnya dilaksanakan pada Program Kemitraan Masyarakat (PKM) ini. Solusi tersebut di antaranya: 1) Mengadakan sosialisasi mengenai upaya motivasi dan transfer ilmu mengenai peluang usaha dan wirausaha mengenai pe- 
manfaatan bahan-bahan alami; 2) Mengadakan pelatihan pengemasan dan pelabellan. kegiatan pengemasan merupakan sistem yang terkoordinasi untuk menyiapkan barang menjadi siap untuk ditransportasikan, didistribusikan, disimpan, dijual, dan dipakai. Pelabelan berisi keterangan produk, tidak boleh mudah lepas, luntur atau lekang karena air, gosokan atau pengaruh sinar matahari (Syarief et al. 1989), 3) Pengoptimalan pembuatan produksi minyak herbal tradisional dengan cara mengadakan peningkatan keterampilan melalui pelatihan pembuatan minyak herbal dengan alat penyulingan sederhana; dan 4) Melakukan pendampingan selama proses pelaksanaan kegiatan pengabdian kepada masyarakat.

\section{METODE PELAKSANAAN KEGIATAN}

\section{Lokasi dan partisipan kegiatan}

Kegiatan pengabdian dilaksanakan di Desa Naga Umbang, Kecamatan Lhoknga, Aceh Besar. Kegiatan dilakukan pada bulan JanuariDesember 2019. Adapun mitra yang terlibat dalam pengabdian ini adalah kelompok tani Pintoe Rimba dari Desa Naga Umbang. Kelompok tani ini berjumlah 20 orang. Lokasi pelaksanaan kegiatan di rumah ketua kelompok tani Pintoe Rimba. Tim yang terlibat adalah satu orang dosen dari Fakultas Pertanian Unsyiah dan dua orang dosen dari Fakultas Teknologi Pertanian Universitas Serambi Mekkah serta dibantu oleh dua orang mahasiswa dari Fakultas Pertanian, Universitas Syiah Kuala.

\section{Bahan dan Alat}

Bahan utama dalam kegiatan ini adalah terdiri dari bahan alami, yaitu jahe, kencur, cengkeh, daun mahkota dewa, dan daun sereh wangi. Sedangkan alat yang digunakan dalam kegiatan produksi minyak herbal tradisional ini meliputi seperangkat alat distilasi untuk menyuling minyak, wadah penampung minyak, pisau, dan alat penumbuk. Kemasan produk menggunakan botol plastik ukuran $100 \mathrm{~mL}$, stiker label, seal, dan sealer penutup botol. Alat distilasi yang digunakan merupakan alat hasil pengembangan penelitian yang telah dilakukan oleh ketua tim pengabdian.

\section{Metode Pelaksanaan}

Metode pelaksanaannya kegiatan PKM ini melalui penyuluhan, diskusi, dan praktik/ demonstrasi secara langsung di lapangan. Dalam pelaksanaannya metode kegiatan pada program pengabdian adalah dengan metode analisis deskriptif yaitu terjun langsung ke masyarakat kelompok Tani Naga Umbang. Pelaksanaannya ada yang dilakukan secara general dan ada juga yang dibagi menjadi beberapa kelompok kecil. Kegiatan penyuluhan diberikan secara tutorial dengan beberapa kelompok kecil, memberikan modul yang berisikan tentang pengenalan alat dan cara penggunaan alat untuk memproduksi minyak herbal tradisional serta teknik pengemasan minyak herbal. Kegiatan penyuluhan ini diselingi dengan diskusi untuk mempertajam pemahaman peserta kegiatan pengabdian. Dalam metode pelaksanaannya, maka pengabdian kepada masyarakat ini di bagi menjadi:

\section{- Pengumpulan informasi}

Tahap ini dilakukan untuk mengidentifikasi potensi yang dimiliki kelompok tani Pintoe Rimba Desa Naga Umbang. Termasuk kondisi dan situasi Desa Naga Umbang, masalah sumber daya manusia, dan potensi sumber daya alam. Pengumpulan data dilakukan dengan cara observasi langsung ke lokasi Pintoe Rimba dan melakukan wawancara dengan ketua kelompok tani. Wawancara juga dilakukan dengan keuchik untuk mengetahui perihal kelompok tani Naga Umbang. Hasil observasi dan wawancara yang dilakukan di lapangan, dapat ditemui kendalakendala dan permasalahan yang sekiranya dapat diperbaiki dan ditingkatkan kinerjanya. Berdasarkan hal tersebut, pembuatan minyak urut dari tanaman sereh wangi menggunakan alat distilasi perlu diterapkan. Selama ini, kelompok tani hanya membeli minyak sereh wangi di pasar tradisional yang belum diketahui kualitasnya. Minyak sereh (bahan utama) inilah yang ditambahkan ke dalam ekstrak jahe, kendur, cengkeh, dan bahan-bahan lainnya. Selain pelatihan pembuatan minyak, program pengabdian ini juga membuat pelatihan pengemasan botol minyak Pintoe Rimba Desa Naga Umbang agar produk terlihat lebih berkualitas dan menarik.

\section{- Persiapan kegiatan}

Tim mengidentifikasi potensi desa, kondisi dan situasi, masalah sumber daya manusia dan sumber daya alam. Kegiatan ini berlangsung selama dua minggu yang dibantu dua orang mahasiswa dan mitra. Tahapan koordinasi merupakan langkah yang sangat perlu dilakukan demi kesuksesan program pengabdian ini. Pihak pengabdi berkoordinasi dengan pihak Lembaga Pengabdian kepada Masyarakat Unsyiah, ma- 
hasiswa, tim pengabdian dan mitra. Tahap koordinasi meliputi persiapan pendanaan, persiapan surat-menyurat, persiapan pengembangan alat destilasi, pembuatan minyak, pengemasan, dan pendampingan dalam pemasaran.

\section{- Pelaksanaan Kegiatan}

Tahap ini merupakan tahap sosialisasi dan penyuluhan, pengembangan alat destilasi minyak, selanjutnya pengemasan produk minyak dan penjualan produk minyak. Tahap percobaan berlangsung selama 3 bulan untuk menganalisis usaha pembuatan minyak. Beberapa metode digunakan untuk memudahkan tahapan kerja yang telah dijelaskan sebelumnya, di antaranya penyajian materi terlebih dahulu menyediakan modul, kemudian metode ceramah, diskusi, demonstrasi dan praktik langsung. Metode ceramah dilaksanakan melalui penyuluhan untuk menyampaikan maksud pelaksanaan kegiatan, serta bagaimana meningkatkan usaha keluarga. Metode demonstrasi digunakan untuk mendemonstrasikan cara mengoperasikan alat destilasi minyak. Metode diskusi dipergunakan untuk mendiskusikan berbagai masalah yang dihadapi baik antar peserta maupun antara peserta dengan tim pengabdi. Mitra juga ikut berpartisipasi untuk menyukseskan program ini, di antaranya menyediakan tempat, waktu dan mencari bahan baku produksi, mencari dan memperluas jaringan pemasaran, memproduksi dan juga memasarkan hasil produksi secara berkelanjutan. Selama satu tahun, pihak pengabdi akan mendampingi dan mengevaluasi keberhasilan pemasaran produk yang dilakukan oleh pihak mitra kelompok tani Pintoe Rimba Desa Naga Umbang.

\section{- Kegiatan pendampingan}

Tahap ini berbentuk kegiatan pendampingan mulai dari kegiatan sosialisasi, penyuluhan, pelatihan pembuatan minyak urut herbal, dan kegiatan pemasaran minyak herbal.

\section{HASIL DAN PEMBAHASAN}

\section{Sosialisasi Kegiatan Pelaksanaan Pengabdian Kepada Masyarakat}

Tim melakukan koordinasi awal dengan ketua kelompok tani Pintoe Rimba dan Kepala Desa Naga Umbang untuk berdiskusi dan meminta izin agar Program Kemitraan Masyarakat (PKM) ini dapat berlangsung dengan lancar. Dari kegiatan ini, tim mendapatkan data jumlah anggota kelompok tani, yaitu berjumlah 20 orang. Tim dan mitra juga menyepakati pelaksanaan kegiatan dilakukan di rumah ketua kelompok tani. Kebutuhan sarana dan prasarana selama kegiatan ini disiapkan oleh tim pengabdian kecuali alat pendukung seperti pemotong dan penumbuk. Gambar 1 menunjukkan tim mengunjungi mitra untuk melihat proses pembuatan minyak urut herbal yang dilakukan selama ini oleh mitra.

\section{Penyuluhan mengenai peningkatan ekonomi keluarga dan wirausaha.}

Kegiatan penyuluhan diadakan akan pentingnya berusaha untuk meningkatkan ekonomi keluarga mengenai bagaimana memanfaatkan peluang usaha yang ada di sekitar lingkungan tempat tinggal mitra (Gambar 2). Adanya transfer ilmu tersebut diharapkan masyarakat kelompok tani Pintoe Rimba Desa Naga Umbang memiliki semangat dan kepercayaan diri dalam berwirausaha serta merubah pola pikir tentang peningkatan ekonomi keluarga. Kegiatan ini dilakukan sebagai upaya motivasi dan transfer ilmu mengenai peluang usaha dan wirausaha melalui pemanfaatan bahan-bahan alami yang

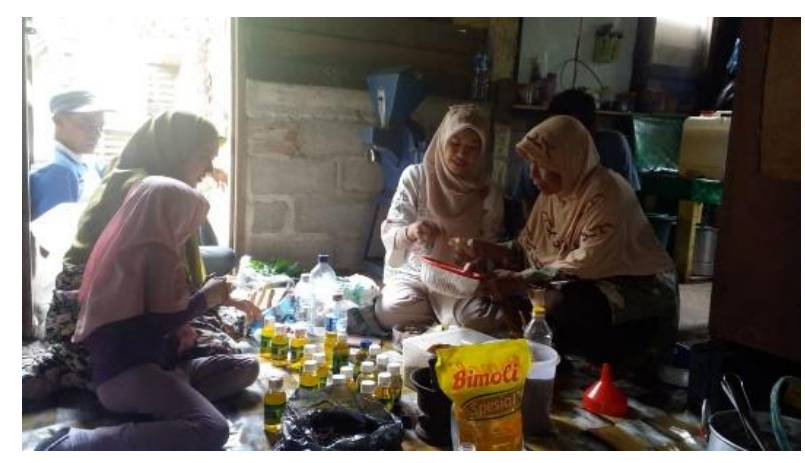

Gambar 1 Kunjungan tim untuk melihat proses pembuatan minyak urut herbal oleh mitra.

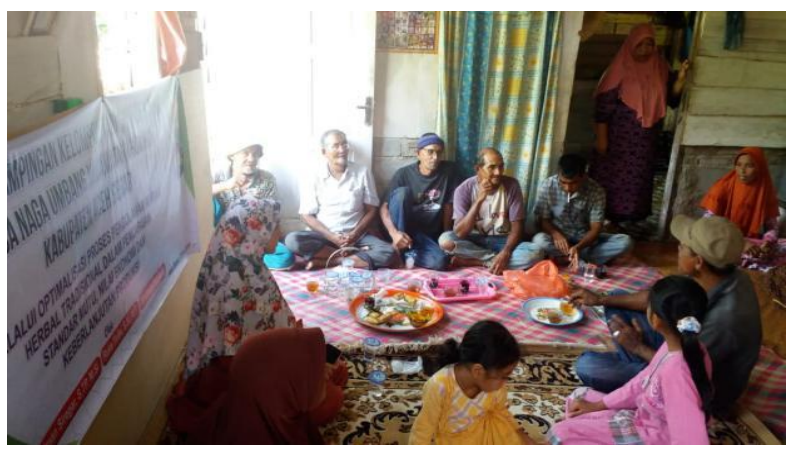

Gambar 2 Penyuluhan kepada kelompok tani Pintoe Rimba tentang pemanfaatan potensi sumber daya alam. 
tidak hanya terfokus pada tanaman sereh wangi, jahe, kencur, dan cengkeh. Namun juga, bahanbahan lainnya yang dapat diolah menjadi produk yang lebih bernilai ekonomi.

Kegiatan ini diikuti oleh 16 orang anggota kelompok tani Pintoe Rimba. Kegiatan ini dilakukan sebagai usaha memberi bekal awal kepada kelompok tani mengenai bagaimana memanfaatkan peluang usaha yang ada di sekitar lingkungan agar mampu meningkatkan perekonomian keluarga. Petani sudah mulai mengolah hasil alamnya menjadi produk yang lebih bernilai ekonomi dan kelompok tani sudah ada yang mulai mengolah hasil tani lainnya menjadi produk seperti bubuk cabe merah kering, bubuk kunyit, dan bubuk ketumbar. Sebelumnya kelompok tani Pintoe Rimba hanya menjual hasil tani ke pasar tanpa mengolahnya. Hasil tani olahan dijual lebih menguntungkan disbandingkan tanpa olahan. Kini, pendapatan kelompok tani meningkat $20 \%$ dari sebelumnya yang terlihat dari permintaan konsumen yang dilaporkan kelompok tani.

\section{Pelatihan Pembuatan Minyak Urut Herbal dengan Alat Distilasi}

Pelaksanaan pembuatan minyak ini dilakukan secara tradisional seperti pembelian minyak sereh yang tidak diproduksi secara mandiri, namun dibeli dengan harga yang cukup mahal. Dengan demikian, diperlukan pengoptimalan pembuatan minyak herbal melalui suatu alat modern untuk membuat minyak sere. Tim pengabdian memberikan alat penyulingan minyak modern di mana diharapkan dapat membantu kelompok tani dari hilir ke hulu. Terutama kelompok tani yang menanam bahan tanaman seperti tanaman sereh wangi atau nilam dapat menyuplai bahan baku ke kelompok tani Pintoe Rimba.

Kelompok tani sudah bisa merangkai alat distilasi dan mengoperasikannya menghasilkan minyak sereh wangi. Sebagai langkah awal, minyak sereh wangi yang dihasilkan oleh petani masih belum optimal karena rendemennya masih rendah. Walaupun rendemennya rendah, kemurnian minyak yang dihasilkan cukup tinggi. Hal ini ditunjukkan yang dari aroma sereh wangi yang dihasilkan begitu kuat. Oleh karena itu, masih dibutuhkan waktu untuk mencari kondisi optimal distilasi untuk menghasilkan rendemen yang tinggi. Hasil pengoperasian pertama, tanaman sereh sebanyak $2 \mathrm{~kg}$ menghasilkan 45 $\mathrm{mL}$ minyak sere. Produk minyak urut herbal yang dihasilkan dari alat distilasi ini memiliki aroma yang lebih kuat daripada produk minyak urut herbal yang dihasilkan sebelumnya. Gambar 3 menunjukkan pemasangan dan demo alat penyulingan di lokasi kelompok tani Pintoe Rimba Desa Naga Umbang.

Beberapa kegiatan pendampingan dilakukan di antaranya pembuatan minyak secara tradisional, namun menggunakan alat yang lebih modern, yaitu alat destilasi minyak tanaman sereh wangi. Pendampingan dilakukan dalam hal cara menggunakan alat destilasi kapasitas 5 kg. Hal ini dilakukan agar kelompok ini memahami cara menggunakan alat ini dengan baik sampai dengan minyak tanaman sere dapat keluar.

\section{Pelatihan Mendesain Kemasan, Pelabellan, serta Memasarkan Produk yang Dihasilkan.}

Pelatihan pengemasan ini dilakukan untuk mengemas produk minyak herbal menjadi lebih menarik dan mampu meningkatkan nilai jual produk minyak herbal yang dihasilkan. Tim mempraktikkan cara mengemas label pada tutup botol kepada mitra menggunakan alat sealer. Alat sealer yang digunakan adalah hairdryer. Pengemasan yang dilakukan dengan pelilinan digantikan dengan alat hairdryer yang membantu pengepresan pada label tutup botol. Alat ini membantu proses pengemasan produk minyak herbal menjadi lebih cepat dan hasil pengemasan menjadi lebih rapi dan tidak terdapat bekas pembakaran (hitam) pada plastik di tutup botolnya.

\section{Tahapan Pendampingan}

Pendampingan yang dilakukan dengan kelompok tani ini adalah di bidang pemasaran, yang dilakukan melalui beberapa kegiatan. Selain secara langsung dari rumah ker rumah, pendampingan yang dilakukan adalah melalui "Minyak Naga Umbang Goes To". Tim pengabdian mendampingi kelompok tani dalam mem-

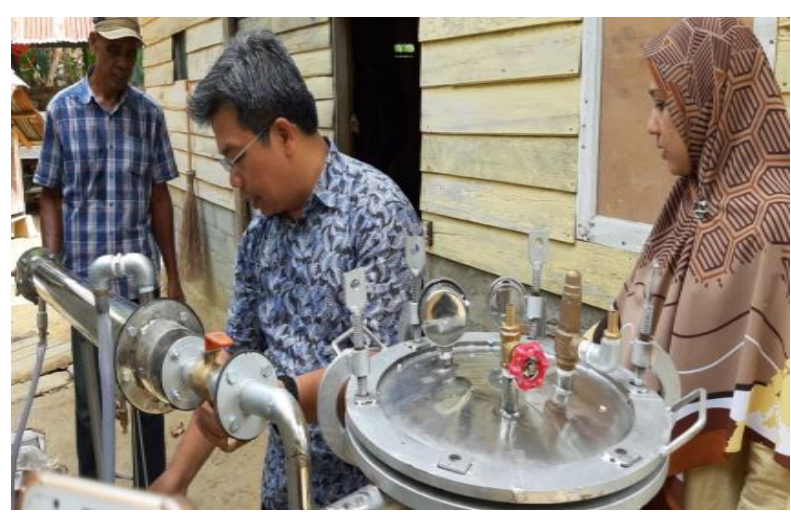

Gambar 3 Pemasangan dan demo alat penyulingan pada kelompok tani Pintoe Rimba. 
perkenalkan minyak Pintoe Rimba ke kalangan Civitas Akademika. Kegiatan yang dilakukan di sekitar Universitas Serambi Mekkah (USM) Banda Aceh. Dalam kegiatan ini dikenalkan juga tahapan kegiatan dan proses pembuatan minyak melalui flyer dan poster yang telah dibuat.

\section{SIMPULAN}

Kegiatan pengabdian kepada masyarakat ini memperkenalkan dan memberikan suatu alat penyulingan minyak yang lebih efisien dalam mengoptimalisasikan produksi minyak herbal kelompok tani Pintoe Rimba. Kegiatan PKM menghasilkan berbagai capaian bagi mitra pengabdian di antaranya adalah mitra sudah mulai termotivasi untuk meningkatkan perekonomian keluarga dengan berwirausaha memanfaatkan potensi alam sekitar, mitra telah cukup cakap dan terampil mengolah bahan alami menjadi minyak herbal tradisional menggunakan alat penyulingan, produk minyak herbal milik mitra memiliki standar mutu minyak yang lebih baik dari sebelumnya, mitra sudah mampu mengemas dan memberikan label pada produk minyak herbal tradisional dengan menggunakan alat pengeseal yang lebih cepat. Keberadaan produk minyak urut herbal milik mitra telah dikenal oleh masyarakat di kota Banda Aceh dan Aceh besar melalui publikasi media online Serambinews.

\section{UCAPAN TERIMA KASIH}

Terima kasih kepada Direktorat Jenderal Riset dan Pengembangan, Kementerian Riset Teknologi dan Pendidikan Tinggi (DPRM Kemenristek Dikti) yang telah mendanai pengabdian kepada masyarakat ini. Juga kepada Lembaga Penelitian dan Pengabdian Masyarakat (LP2M) Universitas Syiah Kuala dan Universitas Serambi Mekkah yang telah berkolaborasi sehingga kegiatan ini dapat berlangsung dengan baik. Tidak lupa ucapan terima kasih juga kami sampaikan kepada kelompok tani Pintoe Rimba yang menjadi mitra dalam kegiatan pengabdian ini.

\section{DAFTAR PUSTAKA}

Al Hanief MM, Al Mushawwir HW, Mahfud. 2013. Ekstraksi Minyak Atsiri dari Akar Wangi
Menggunakan Metode Steam-Hydro distillation dan Hydro distilation dengan Pemanas Microwave. Jurnal Teknik Pomits. Vol. 2. No. 2.

Arpi N. 2013. Pembuatan Minyak Kemenyan (Minyak obat Tradisional Khas Aceh) denganvariasi Bahan Baku Minyak dan Konsentrasi Bahan Pewangi. Jurnal Teknologi dan Pertanian Indonesia. 5(1): 17-22.

Dahlian E, Hartoyo. 1998. Pembuatan Minyak Cendana dengan Cara Penyulingan Uap Langsung. Buletin Penelitian Hasil Hutan. 15(6): 385-394.

Effendi EP, Widjanarko SB. 2014. Distilasi dan Karakterisasi Minyak Atsiri Rimpang Jeringau. Minyak Atsiri Rimpang Jeringau (Acorus Calamus) dengan Kajian Lama Waktu Distilasi dan Rasio Bahan Pelarut. Jurnal Pangan dan Agroindustri. 2(2_: 1-8.

Hanum SMF, Purwanti Y, Khumairoh IR. 2015. Efektivitas pijat oksitosin terhadap produksi ASI. Midwiferia. 1(1): 1-6. https://doi.org/ 10.21070/mid.v1i1.343

Iryani, Deka SA. 2018. Pembuatan minyak atsiri dari kulit jeruk purut (citrus histrix) dengan metode ekstraksi. Dalam: Prosiding Seminar Hasil Penelitian (SNP2M) Bidang Ilmu Teknik Kimia, Kimia, Teknik Lingkungan, Biokimia Dan Bioproses. Hal: 159-161.

Juniarti, Yuhernita, Endrini S. 2011. Destilasi minyak atsiri daun surian sebagai krim pencegah gigitan nyamuk Aedes aegypty L. Makara Journal of Sains. 15(1): 38-42.

Karo EIB, Kaban FO. 2019. Optimalisasi Tumbuh Kembang Bayi melalui Edukasi, Terapi Pijat Bayi (Baby Massage) dan Senam Bayi (Baby Gym) di Klinik Bersalin Kota Medan dan Kabupaten Deli Serdang. Jurnal Riset Hesti Medan. 4(1): 33-37. https://doi.org/ 10.34008/jurhesti.v4i1.60

Paryono, Prihati DR. 2017. Pengaruh Pijat Refleksi Terhadap Penurunan Nyeri Haid pada Wanita di Panti Yatim Putri Daerah Klaten. Jurnal Terpadu Ilmu Kesehatan. 6(2): 159167. https://doi.org/10.37341/interest. v6i2.96

Prasetyo FY. 2018. Ekstraksi minyak atsiri dari bunga cengkeh dengan menggunakan metode ultrasonik. Publikasi Ilmiah. Surakarta (ID): Universitas Muhammadiyah. 
Setyawan EP, Pytratama A, Ajeng WRP, Rengga. 2012. Optimalisasi Yield Etil P Metoksisinamat pada Ekstraksi Oleorisin Kencur (Kaempferia galanga) Menggunakan Pelarut Etanol. Jurnal Bahan Alam terbarukan. 1(2): 31-38.

Supardi S, Susyanty AL. 2010. Penggunaan Obat Tradisional dalam Upaya Pengobatan Sendiri di Indonesia (Analisis Data Susenas Tahun 2007). Buletin Penelitian Kesehatan. 38(2): 80-89.

Syarief RS, Santausa, Isyana B. 1989. Teknologi Pengemasan Pangan. Bogor (ID):
Laboratorium Rekayasa Proses Pangan Pusat antar Universitas dan Gizi IPB.

Rezky RA, Hasneli Y, Hasanah O. 2015. Pengaruh Terapi Pijat Refleksi Kaki Terhadap Tekanan Darah pada Penderita Hipertensi Primer. Jom. 2(2): 1454-1462.

Rusnoto N, Cholifah I, Retnosari. 2015. Pemberian Kompres hangat Nenakai Jahe Untuk Meringankan Skala Nyeri Pada Pasien Asam Urat di Desa Kedungwungu, Kecamatan Tegowanu, Kabupaten Grobokan. Jurnal Ilmu Keperawatan Dan Kebidanan. 6(1): 29-39. 